\title{
บusisersaly
}

\section{Poly(caprolactone)-Based Coatings on 3D-Printed Biodegradable Implants: A Novel Strategy to Prolong Delivery of Hydrophilic Drugs}

Stewart, S., Dominguez-Robles, J., Mcllorum, V., Gonzalez, Z., Utomo, E., Mancuso, E., Lamprou, D., Donnelly, R. F., \& Larraneta, E. (2020). Poly(caprolactone)-Based Coatings on 3D-Printed Biodegradable Implants: A Novel Strategy to Prolong Delivery of Hydrophilic Drugs. Molecular Pharmaceutics, 17(9), 3487-3500. https://doi.org/10.1021/acs.molpharmaceut.0c00515

Link to publication record in Ulster University Research Portal

\section{Published in:}

Molecular Pharmaceutics

Publication Status:

Published (in print/issue): 08/09/2020

DOI:

10.1021/acs.molpharmaceut.0c00515

\section{Document Version}

Publisher's PDF, also known as Version of record

\section{General rights}

Copyright for the publications made accessible via Ulster University's Research Portal is retained by the author(s) and / or other copyright owners and it is a condition of accessing these publications that users recognise and abide by the legal requirements associated with these rights.

\section{Take down policy}

The Research Portal is Ulster University's institutional repository that provides access to Ulster's research outputs. Every effort has been made to ensure that content in the Research Portal does not infringe any person's rights, or applicable UK laws. If you discover content in the Research Portal that you believe breaches copyright or violates any law, please contact pure-support@ulster.ac.uk. 


\title{
Poly(caprolactone)-Based Coatings on 3D-Printed Biodegradable Implants: A Novel Strategy to Prolong Delivery of Hydrophilic Drugs
}

\author{
Sarah A. Stewart, Juan Domínguez-Robles, Victoria J. Mcllorum, Zoilo Gonzalez, Emilia Utomo, \\ Elena Mancuso, Dimitrios A. Lamprou, Ryan F. Donnelly, and Eneko Larrañeta*
}

Cite This: https://dx.doi.org/10.1021/acs.molpharmaceut.0c00515

Read Online

\section{ACCESS | Lill Metrics \& More | 回 Article Recommendations | (1) Supporting Information}

ABSTRACT: Implantable devices are versatile and promising drug delivery systems, and their advantages are well established. Of these advantages, long-acting drug delivery is perhaps the most valuable. Hydrophilic compounds are particularly difficult to deliver for prolonged times. This work investigates the use of poly(caprolactone) (PCL)-based implant coatings as a novel strategy to prolong the delivery of hydrophilic compounds from implantable devices that have been prepared by additive manufacturing (AM). Hollow implants were prepared from poly(lactic acid) (PLA) and poly(vinyl alcohol) (PVA) using fused filament fabrication (FFF) AM and subsequently coated in a PCL-based coating. Coatings were prepared by solution-casting mixtures of differing molecular weights of PCL and poly(ethylene glycol) (PEG). Increasing the proportion of low-molecular-weight

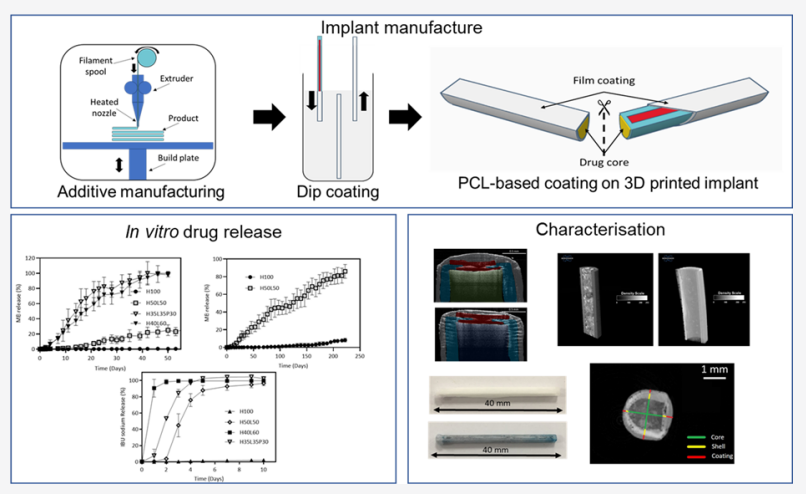
PCL up to $60 \%$ in the formulations decreased the crystallinity by over $20 \%$, melting temperature by over $4{ }^{\circ} \mathrm{C}$, and water contact angle by over $40^{\circ}$, resulting in an increased degradation rate when compared to pure high-molecular-weight PCL. Addition of 30\% PEG to the formulation increased the porosity of the formulation by over 50\% when compared to an equivalent PCL-only formulation. These implants demonstrated in vitro release rates for hydrophilic model compounds (methylene blue and ibuprofen sodium) ranging from 0.01 to $34.09 \mathrm{mg} / \mathrm{day}$, depending on the drug used. The versatility of the devices produced in this work and the range of release rates achievable show great potential. Implants could be specifically developed in order to match the specific release rate required for a number of drugs for a wide range of conditions.

KEYWORDS: poly(caprolactone) coatings, poly(ethylene glycol), implantable drug delivery, hydrophilic drugs, additive manufacturing, $3 D$ printing, fused filament fabrication

\section{INTRODUCTION}

Implantable drug delivery devices offer many advantages including improved patient compliance and reduced side effects, among others. ${ }^{1-4}$ These are achieved by maintaining a therapeutic concentration over a prolonged time frame, without the need for frequent tablets or injections. ${ }^{5}$ They can be used for a wide variety of clinical applications including women's health, oncology, ocular disease, pain management, infectious disease, and central nervous system disorders. ${ }^{3,6}$ The majority of implant devices are polymeric rods designed to be inserted subcutaneously or intramuscularly, and the most common method of insertion is via a needle or by surgical implantation. ${ }^{7,8}$ This can be relatively traumatic for the patient in comparison to oral drug delivery. However, the long-term drug delivery and improvements in patient compliance that this route of delivery offers may outweigh this disadvantage. This could be particularly important in chronic conditions where poor patient compliance is a challenge, for example in human immunodeficiency virus (HIV) or mental health conditions.
Many implants are made of non-biodegradable materials, such as silicone (e.g., Norplant ${ }^{9}$ ) or poly(ethylene-vinyl acetate) (e.g., Nexplanon ${ }^{10}$ and Ocusert ${ }^{11}$ ) and, therefore, need to be removed from the body once they have achieved their purpose. This removal can often be distressing for the patient and may be more invasive than the insertion of the device. $^{12}$ Development of a device made entirely from biodegradable polymers could circumvent this issue, as the device would biodegrade naturally to form products that can be excreted easily by the body once the device has achieved its effect, ${ }^{5}$ although still offering the possibility of early removal if adverse effects necessitated it. ${ }^{13}$ Commonly used biodegradable (or soluble), biocompatible, and U.S. Food and Drug

Received: May 11, 2020

Revised: July 14, 2020

Accepted: July 16, 2020

Published: July 16, 2020 
(A)

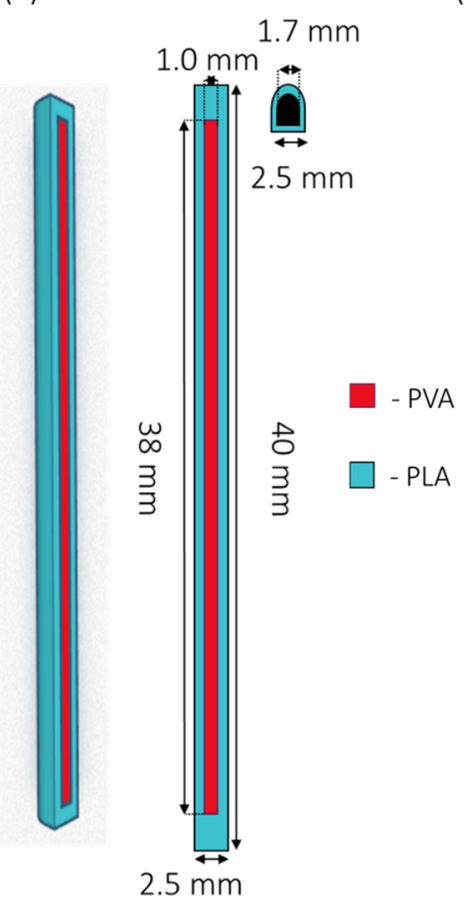

(B)

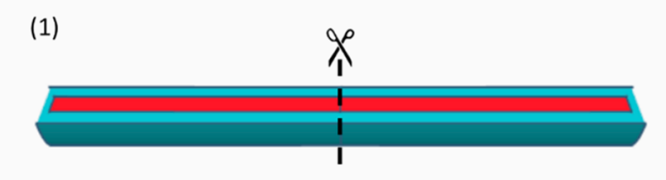

(2)

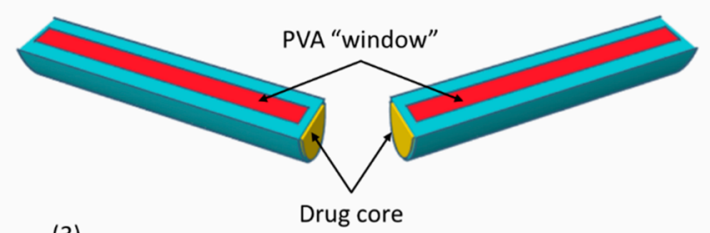

(3)

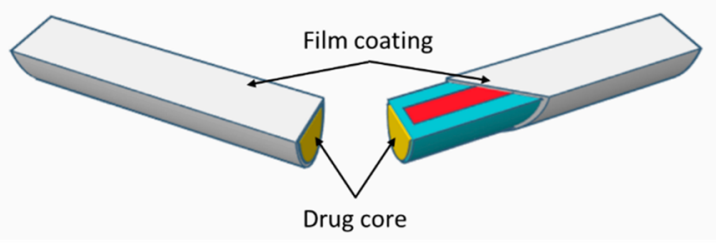

Figure 1. (A) CAD design used to produce the AM implant. (B) (1) Uncoated implant, (2) cross-sectional view of an uncoated implant, and (3) cross-sectional view of a coated implant.

Administration (FDA)-approved polymers include poly(lactic acid) (PLA), poly(vinyl alcohol) (PVA), and poly(caprolactone) (PCL). ${ }^{5,14-16}$ These polymers have been widely used for biomedical applications including cardiovascular stents ${ }^{15}$ and implants. $5,14,16,17$

Hot-melt extrusion (HME), solution casting, injection molding, and additive manufacturing (AM) (also known as $3 \mathrm{D}$ printing) are common methods for the manufacture of implants ${ }^{5}$ and commonly produce devices in which the drug is dispersed throughout (matrix-type implants). This has some drawbacks and limits the number of drugs which are suitable due to the high temperatures or solvents used. ${ }^{5}$ In comparison, reservoir-type devices may be fabricated and drug loaded separately, thus limiting drug exposure to adverse conditions. The aim of this study is to use AM, specifically fused filament fabrication (FFF), to produce a reservoir-type implantable device. In this way, the device is manufactured separately from the drug compound and, therefore, limits the drug exposure to high temperatures or solvents. This technology has already been investigated for the manufacture of oral dosage forms, implants, and protheses. ${ }^{18,19}$ The sustained delivery of hydrophilic drugs is a particular challenge, and numerous strategies to prolong their release have been investigated including colloidal systems, nanoparticles, gold nanoclusters, and liposomes. ${ }^{20-22}$ In order to prolong the release from the implants produced in this work, they will subsequently be coated in a polymeric film, which will control the drug release from the device.

Hollow implantable devices, made from biocompatible polymers (PLA and PVA), were prepared using FFF AM. Subsequently, these devices were coated with polymeric films made from PCL and poly(ethylene glycol) (PEG). The polymeric films and the resulting devices were characterized using a range of techniques including $\mathrm{X}$-ray micro-computer tomography $(\mu$-CT), attenuated total reflectance-Fourier transform infrared (ATR-FTIR), X-ray diffraction (XRD), contact angle goniometry (CAG), and differential scanning calorimetry (DSC). Drug release from the designed devices was characterized by delivering hydrophilic model compounds (methylene blue (MB) and ibuprofen sodium (IBU sodium)) using an in vitro release model.

\section{MATERIALS AND METHODS}

2.1. Materials. Granulated PLA (Ingeo Biopolymer 4043D) was purchased from NatureWorks (Minnetonka, MN, USA). Filament PVA was purchased from Ultimaker (Geldermalsen, The Netherlands). PCL $6506\left(M_{\mathrm{W}}=50000\right.$ $\mathrm{Da}$, i.e., high molecular weight), henceforth referred to as $\mathrm{H}$ PCL, and PCL $2054\left(M_{\mathrm{W}}=550 \mathrm{Da}\right.$, i.e., low molecular weight), henceforth referred to as L-PCL, were provided by Perstorp (Malmö, Sweden). MB, IBU sodium, PEG $\left(M_{\mathrm{W}}=\right.$ $1000 \mathrm{Da})$, and phosphate-buffered saline (PBS) tablets $(\mathrm{pH}$ 7.4) were purchased from Sigma-Aldrich (Dorset, UK). Dichloromethane (DCM) was obtained from Merck (Darmstadt, Germany).

2.2. Methods. 2.2.1. Implant Design and Manufacture. Single-screw HME was used to produce the PLA filament for the implant manufacture in combination with the PVA filament. As described previously by Stewart et al., ${ }^{23}$ PLA pellets were added to a filament extruder (3Deveo, Utretch, The Netherlands) at an extrusion speed of $5 \mathrm{rpm}$ and a filament fan speed of $70 \%$. The temperature was controlled between 170 and $190{ }^{\circ} \mathrm{C}$.

A hollow implant was designed (Figure 1A) using computeraided design (CAD) software and printed using an Ultimaker 3 AM system (Ultimaker, Geldermalsen, The Netherlands) using Cura software. The Ultimaker 3 system was equipped with 0.4 $\mathrm{mm}$ extruder nozzles loaded with PLA and PVA filament, respectively. The print speed was $70 \mathrm{~mm} / \mathrm{s}$, the print 
temperature used was $205^{\circ} \mathrm{C}$, the build plate temperature was $85^{\circ} \mathrm{C}$, and the layer height used was $0.1 \mathrm{~mm}$. After the AM process, implants were loaded manually with solid drug powder core (either MB $(68.6 \pm 5.1 \mathrm{mg})$ or IBU sodium $(68.1 \pm 3.0 \mathrm{mg})$ ). Subsequently, the implants were coated by solution casting ${ }^{13}$ with a biodegradable PCL or PCL/PEG film to control the drug release from the implant (Figure 1B). The thickness of each of the implant coatings was analyzed using a digital calliper and the PCL solution concentration altered, if necessary, to produce coatings with the same thickness.

2.2.2. PCL Film Formulation. Films of varying proportions of H-PCL, L-PCL, and PEG 1000 were prepared by solution casting. ${ }^{13}$ The appropriate ratios of constituents $(1.5 \mathrm{~g})$ (Table 1) were dissolved in $10 \mathrm{~mL}$ of DCM, $5 \mathrm{~g}$ of the resulting solution was poured into a glass Petri dish, and the DCM was allowed to evaporate at room temperature $\left(20^{\circ} \mathrm{C}\right)$ to form films. $^{13}$

Table 1. Composition of Polymeric Films Prepared by Solution Casting

\begin{tabular}{lccc} 
& \multicolumn{3}{c}{ composition (\%) } \\
\cline { 2 - 4 } formulation & H-PCL & L-PCL & PEG 1000 \\
H100 & 100 & 0 & 0 \\
H70L30 & 70 & 30 & 0 \\
H50L50 & 50 & 50 & 0 \\
H40L60 & 40 & 60 & 0 \\
H45L45P10 & 45 & 45 & 10 \\
H40L40P20 & 40 & 40 & 20 \\
H35L35P30 & 35 & 35 & 30 \\
H30L30P40 & 30 & 30 & 40 \\
\hline
\end{tabular}

2.2.3. PCL Film Characterization. ATR-FTIR spectrometry was used to investigate any chemical interactions between the materials within each of the films. An Accutrac FT/IR-4100 series (Jasco, Essex, UK) equipped with MIRacle diamond ATR was used at room temperature $\left(20{ }^{\circ} \mathrm{C}\right)$. The IR transmission spectra were recorded between 600 and 4000 $\mathrm{cm}^{-1}$ with a resolution of $4.0 \mathrm{~cm}^{-1}$. An average of 64 repeat scans were taken to obtain each spectrum.

The thermal properties of the PCL films were investigated using DSC. Analysis was carried out on samples of each formulation on a DSC Q100 differential scanning calorimeter (TA Instruments, New Castle, DE, USA). Samples of each film were heated from 0 to $100{ }^{\circ} \mathrm{C}$ at a rate of $10{ }^{\circ} \mathrm{C} / \mathrm{min}$. The melting temperature was determined from the peak of the DSC endotherm.

The crystalline structure of the films was evaluated by XRD analysis. XRD spectra were recorded at room temperature using a D5000 diffractometer (Siemens, Munich, Germany) with a Kristalloflex 710 generator with filtered $\mathrm{Cu} \mathrm{K} \alpha$ radiation $(\lambda=1.5405 \AA ; 40 \mathrm{kV} ; 30 \mathrm{~mA})$. Data were collected in the $2 \theta$ range from $10^{\circ}$ to $70^{\circ}$ with a step of $0.02^{\circ}$ and counting time of $1 \mathrm{~s} / \mathrm{step}$. The crystallinity of each of the films was calculated using eq 1 after deconvoluting the peaks present in the diffractograms.

$$
X_{\mathrm{c}}=\frac{I_{\mathrm{c}}}{I_{\mathrm{c}}+I_{\mathrm{a}}}
$$

where $I_{c}$ represents the area under crystalline peaks and $I_{a}$ represents the area under amorphous halos. ${ }^{24}$
Degradation of each of the PCL films was investigated. The initial dry weights $\left(W_{0}\right)$ of three replicates $(1.0 \mathrm{~cm} \times 2.5 \mathrm{~cm}$ and $89.58( \pm 23.00) \mu \mathrm{m}$ thick $)$ of each film were recorded. The films were then placed in $5 \mathrm{~mL}$ of PBS $(\mathrm{pH} \mathrm{7.4})$ at $37^{\circ} \mathrm{C}$ with shaking at $40 \mathrm{rpm}$. The films were removed at defined time points, excess water was removed, and the weights at time $t$ were recorded $\left(W_{t}\right)$. The films were then placed in $5 \mathrm{~mL}$ of fresh PBS ( $\mathrm{pH} \mathrm{7.4)}$ at $37^{\circ} \mathrm{C}$.

The percentage weight remaining was calculated using eq 2 :

$$
\% \text { wt remaining }=\frac{W_{t}}{W_{0}} \times 100
$$

The contact angle of deionized water with the surface of each the films was measured using the sessile drop method. For this purpose, an Attension Theta tensiometer (Biolin Scientific, Gothenburg, Sweden) was used, and OneAttension software was used to analyze the results. ${ }^{25}$ Each reported contact angle is a mean of three measurements taken from random areas on each film formulation. The volume of each droplet used was kept constant $(4 \mu \mathrm{L})$, and each contact angle reported was measured $1.94 \mathrm{~s}$ after release of the droplet.

In addition, the porosity of each of the films was also evaluated in terms of mercury intrusion porosimetry (MIP). All tests were carried out on an Autopore IV 9500 instrument (Micromeritics, Norcross, GA, USA). Prior to analysis, all samples were dried at $40{ }^{\circ} \mathrm{C}$ and placed into a penetrometer to ensure the correct mercury fill into the voids. The relationship between applied pressure and pore size is defined by the Washburn equation, which assumes a relationship between the applied pressure and pore diameter using physical properties of a non-wetting material (in this case, mercury which has a contact angle of $141^{\circ}$ with the test materials). The applied pressure ranged from 1 to 60000 psi.

Finally, a TCS SP8 laser scanning confocal microscope (Leica, Wetzlar, Germany) was used to acquire sequential images of a H35L35P30 film containing a hydrophobic dye (Nile red) and a hydrophilic dye (fluorescein). Excitation at 488 and $552 \mathrm{~nm}$ was achieved using a laser, and photons were collected via HyD Leica spectral detectors.

2.2.4. Implant Characterization. Optical coherence tomography (OCT) using an EX1301 OCT microscope (Michelson Diagnostics, Kent, UK) enabled visualization of implant coatings and the drug within the implant cavity. Additionally, $\mathrm{X}$-ray $\mu$-CT scans were performed on the implants following the same methodology reported by Matthew and DominguezRobles et al. ${ }^{26,27}$ Briefly, the $3 \mathrm{D}$ reconstruction volumes and inner structures of the implants were observed by using a Skyscan 1275 system (Bruker, Billerica, MA, USA) with a Hamamatsu L11871 source. The microfocus of the X-ray source of the $\mu$-CT scanner had maximum voltage of $40 \mathrm{kV}$ and maximum current of $250 \mu \mathrm{A}$. Samples were mounted vertically on dental wax and positioned $59.791 \mathrm{~mm}$ from the source, and the camera-to-source distance was $286 \mathrm{~mm}$. No filter was applied for an exposure time of $49 \mathrm{~ms}$. The images generated were $1944 \times 1413$ pixels with a resolution of $17 \mu \mathrm{m}$ per pixel. The data were then collected, and Data Viewer and CT-An software were used to analyze them. Finally, CTvol software was applied to generate 3D reconstruction images.

2.2.5. In Vitro Release. Implants were loaded with $\mathrm{MB}$ or IBU sodium, placed in $500 \mathrm{~mL}$ of PBS ( $\mathrm{pH} \mathrm{7.4)}$ at $37^{\circ} \mathrm{C}$, and shaken at $40 \mathrm{rpm}$. Samples $(0.5 \mathrm{~mL})$ of the release medium were taken at specified time points and replaced with equal 
volumes of PBS ( $\mathrm{pH} 7.4) .^{28} \mathrm{MB}$ and IBU sodium were quantified using UV spectroscopy and RP-HPLC, respectively, as previously described by Stewart et al. ${ }^{23}$ Total drug release at each time point was calculated using eq 3 , taking into account sample that had been removed previously to offset any dilution from sample removal and replacement with fresh medium.

$$
\% \text { drug release }=\frac{W_{t}+W_{\mathrm{s}}}{W_{0}} \times 100
$$

where $W_{t}$ is the weight of drug released at time $t, W_{\mathrm{s}}$ is the weight of drug removed in all previous samples, and $W_{0}$ is the weight of drug in the implant at $t=0$.

2.3. Data Analysis. 2.3.1. Similarity and Difference Factor. Release profiles from each of the implants were compared by calculating and comparing the difference $\left(F_{1}\right)$ and similarity $\left(F_{2}\right)$ factors. $F_{1}$ was calculated using eq 4 and measures the percentage difference between two curves at each time point; it is a measurement of the relative error between the two curves.

$$
F_{1}=\left\{\left[\sum_{t=1}^{n}\left(R_{t}-T_{t}\right)\right] /\left[\sum_{t=1}^{n} R_{t}\right]\right\} \times 100
$$

where $n$ is the number of time points, $R_{t}$ is the reference dissolution value at time $t$, and $T_{t}$ is the test dissolution value at time $t^{29,30}$

$F_{2}$ is calculating using eq 5 and is a logarithmic transformation of the sum-squared error of differences between the test and reference products over all time points, $n$.

$$
F_{2}=50 \log \left\{\left[(1 / n) \sum_{t=1}^{n}\left(R_{t}-T_{t}\right)\right]^{-0.5} \times 100\right\}
$$

In order for two dissolution profiles to be considered similar, the $F_{1}$ value should be lower than $15(0-15)$ and the $F_{2}$ value should be more than $50(50-100))^{29,30}$ The mean profiles are assumed to differ by no more than $15 \%$ if $F_{2}$ is between 50 and $100 .^{31}$

2.3.2. Statistical Analysis. Where appropriate all data was expressed as a mean \pm standard deviation (SD) and compared using one-way analysis of variance (ANOVA) with Tukey's HSD post hoc analysis. Moreover, Kruskal-Wallis test followed by Dunn post hoc analysis was used to compare drug release rates from implants coated with different formulations. In all cases, $p<0.05$ was the minimum value considered acceptable for rejection of the null hypothesis.

\section{RESULTS AND DISCUSSION}

3.1. Implant Design and Manufacture. PLA and PVA are widely used materials in $\mathrm{AM}$, and as such the conditions have been previously optimized. ${ }^{2,32}$ Moreover, these polymers have been approved by the FDA for pharmaceutical and medical applications, and they have been extensively used for drug delivery applications. ${ }^{33-35}$ Implant dimensions of $2.5 \times$ $40.0 \mathrm{~mm}$ were chosen because this shape and size have already been shown to be acceptable in commercially available products (e.g., Nexplanon) and applicator devices have already been developed for an implant of these dimensions. ${ }^{36}$ These types of implants have been described before for drug release purposes. ${ }^{23}$ However, it was reported that they were not ideal to sustain the release of drugs for prolonged periods of time. Accordingly, a coating capable of sustaining drug permeation will be a great improvement. For this purpose, a PCL-based coating was designed.

3.2. PCL Film Characterization. PCL has been extensively used for pharmaceutical and medical applications. ${ }^{5,37-39}$ PCL was chosen as the basis of the polymeric film because it is biodegradable, biocompatible, and low cost. ${ }^{12,40}$ The main applications of this type of polymer have been the preparation of nanoparticles for drug delivery or its use as scaffold for tissue regeneration. ${ }^{37,38}$ PCL has previously been used as a rate-controlling membrane. ${ }^{13}$ However, we propose a novel approach where the properties of the membrane, including its drug permeation, will be tailored by adjusting the coating composition. To the best of our knowledge this type of coating formulation for sustained drug delivery has not been reported before.

Before coating implants, different PCL formulations were prepared and characterized (Table 1). FTIR was used to analyze the resulting formulations (Figure 2). Typical PCL

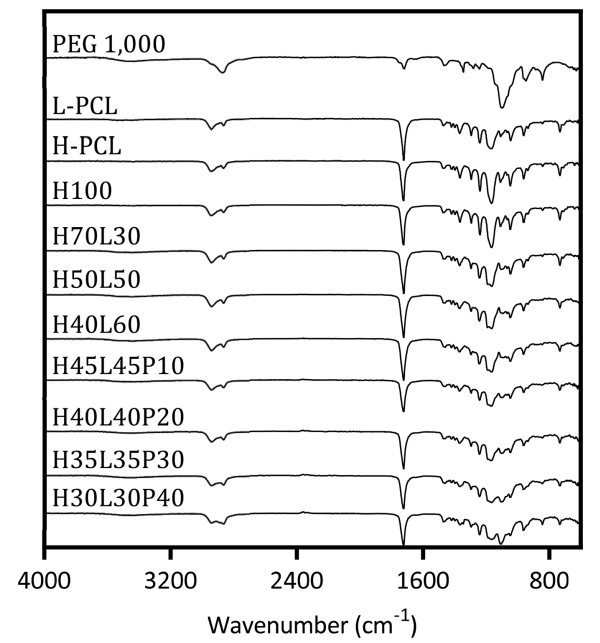

Figure 2. ATR-FTIR spectra of each of the polymeric film formulations.

absorption bands at $\sim 1295 \mathrm{~cm}^{-1}$ ( $\mathrm{C}-\mathrm{O}$ and $\mathrm{C}-\mathrm{C}$ stretching), $\sim 1730 \mathrm{~cm}^{-1}(\mathrm{C}=\mathrm{O})$, and $\sim 2940$ and $\sim 2860 \mathrm{~cm}^{-1}(\mathrm{C}-\mathrm{H})$ are present in all formulations containing $\mathrm{PCL}^{41,42}$ (Figure 2). The spectra of each of the blends showed the characteristic peaks of the constituent polymers. Absorption bands at 1725 and $1100 \mathrm{~cm}^{-1}$ are present and have been previously reported to be associated with the formation of blends between PCL and PEG. ${ }^{39}$ Broad bands at $2945 \mathrm{~cm}^{-1}$ (associated with $\mathrm{C}-\mathrm{H}$ vibrations in PCL) and $2868 \mathrm{~cm}^{-1}$ (attributed to $\mathrm{C}-\mathrm{H}$ stretching within PEG) are evidence of an association between the functional groups of the constituent polymers. ${ }^{39}$ Peaks of all pure materials are present in each formulation, but no new peaks are formed, indicating that no covalent interactions have occurred between the compounds and confirming the formation of a polymer blend rather than a copolymer.

DSC was performed on each of the films to ensure that they all formed miscible blends that demonstrated a single melting point (Figure 3). Neither L-PCL nor PEG 1000 showed a separate melting point at $18-23{ }^{\circ} \mathrm{C}^{43}$ and $37-40{ }^{\circ} \mathrm{C},{ }^{44,45}$ respectively. This reinforces the results from FTIR, which suggests there are no covalent interactions occurring between PCL and PEG 1000. It has been previously shown that PCLPEG mixtures show discrete melting points for both PCL and PEG. ${ }^{46}$ However, these studies used different molecular 

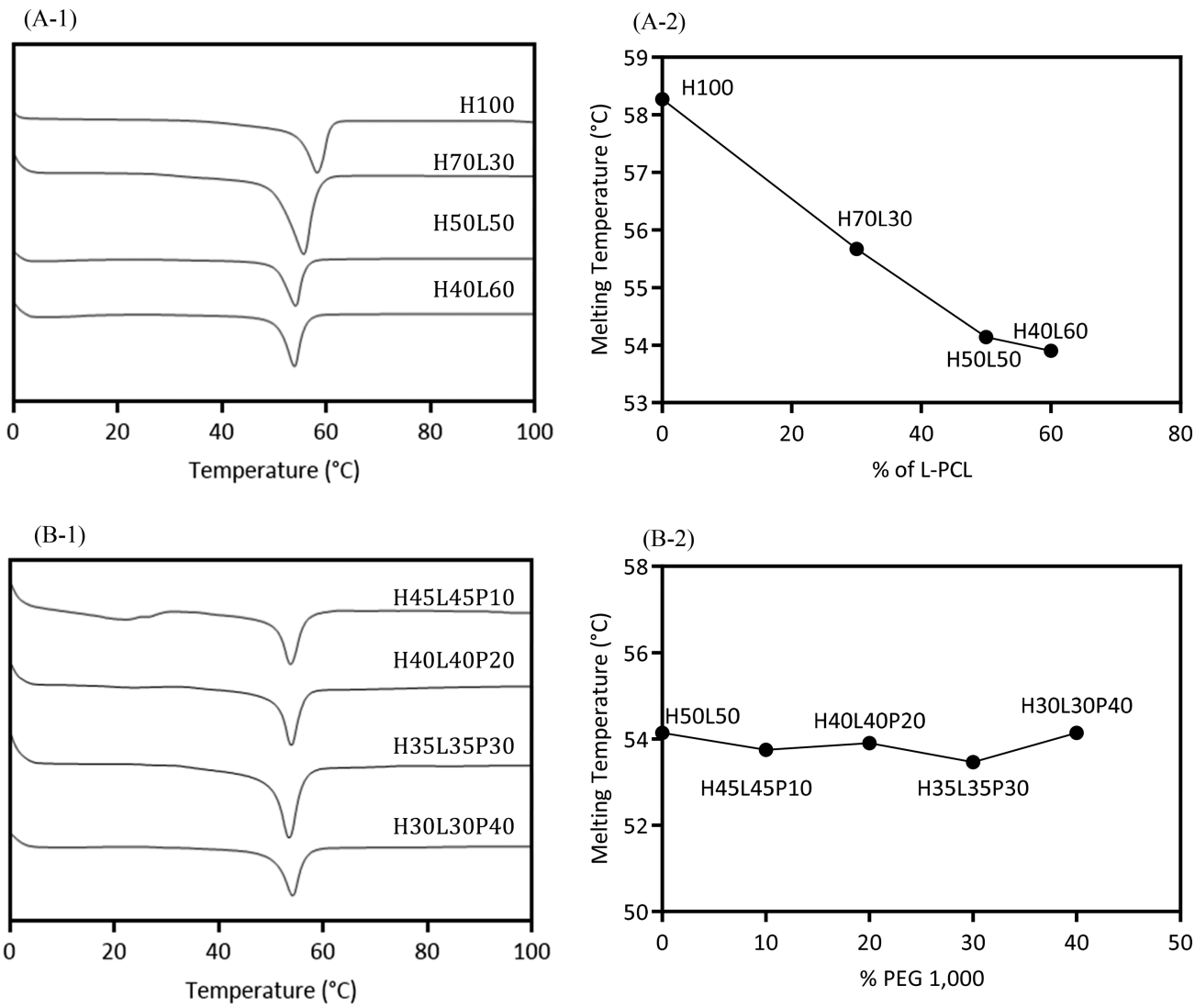

Figure 3. Influence of (A) L-PCL and (B) PEG 1000 on (1) DSC endotherm and (2) melting temperature of polymeric films. Exo Up.

weights of PEG, suggesting that molecular weight has an effect on the miscibility of the compounds. It is observed that addition of L-PCL, which is liquid at room temperature $(20$ ${ }^{\circ} \mathrm{C}$ ), has the effect of lowering the melting temperature of $\mathrm{H} 100$, and that as the proportion of L-PCL is increased, the melting point is further reduced. From Figure 3B1-2, it is observed that addition of PEG 1000 to the films does not further reduce the melting point of the membranes. It has been reported that an increase in the degree of crystallinity of PCL is observed with the addition of PEG as a result of the plasticizing effect of PEG. ${ }^{47,48}$ It could be that the mobile PEG chains improve molecular chain mobility, thus accelerating crystallization rate and acting as sites for PCL crystal growth, as has been previously reported for PLA. ${ }^{48}$

Figure S1A (see Supporting Information) shows DSC thermograms for H-PCL and PEG 1000 mixtures. These thermograms show that when PEG 1000 is added to H-PCL, the melting point of PCL decreases as observed previously. Interestingly, two melting points can be observed clearly for samples containing 30 and 40\% PEG 1000. This was also observed in samples containing $20 \%$, but this peak is small in comparison to those seen at higher concentrations. The melting point can be attributed to the presence of free PEG 1000 chains not mixed with PCL chains. This behavior is not seen in the films containing L-PCL. PEG 1000 and L-PCL are miscible. Accordingly, it can be hypothesized that the presence of L-PCL is required to mix H-PCL and PEG 1000. It is important to note that this behavior depends on the molecular weight, as PCL-PEG 600 films did not show two melting points (Figure S1B, Supporting Information).

$\mathrm{XRD}$ was used to evaluate the crystallinity of the samples. Crystalline peaks for PCL are observed at $21.5^{\circ}, 22^{\circ}$, and $23.7^{\circ}$ and are attributed to (110), (111), and (200) reflection planes of the orthorhombic crystal while an amorphous halo is observed at $20.5^{\circ}$, which corresponds to previously reported results $^{24,39,41}$ (Figure 4A,B). These peaks are present in all formulations, suggesting that the crystalline structure remains unaltered. In order to calculate the degree of crystallinity, XRD plots were deconvoluted (Figure 4C) to obtain the area of each individual peak.

The addition of L-PCL results in a reduction in crystallinity (Figure 4D). Some samples show a slight deviation from this trend that can be attributed to the deconvolution and fitting process. This reduction in crystallinity supports the reduction in melting temperature observed as the proportion of L-PCL is increased. Accordingly, it can be concluded that the presence of L-PCL will reduce the crystallinity of the samples. On the other hand, an additional crystalline peak appears in the spectra at $18.5^{\circ}$ for H30L30P40 (40\% PEG content). This peak is characteristic of PEG crystalline domains. ${ }^{39}$ This explains the increased crystallinity for this formulation, compared to those with lower PEG 1000 concentration. As the proportion of PEG 1000 in the films is increased to $40 \%$, an increase in crystallinity is observed (Figure 4E).

PCL is known to have a long degradation time, up to two years, but this is dependent on molecular weight. ${ }^{42}$ As such, a low-molecular-weight PCL was chosen to be added to H-PCL to assess the effect on degradation. PCL is also easily miscible with other polymers and can form copolymers and blends. ${ }^{40,49}$ Therefore, PEG 1000 was chosen as another component to assess how it would affect the degradation rate of the films. Mixtures of L-PCL and PEG 1000 were not tested, as these have been previously shown to degrade rapidly and are unlikely to be useful for the pronged release of hydrophilic 
(A)

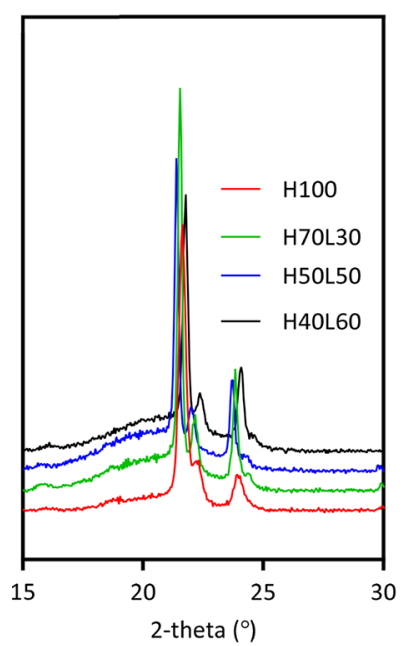

(D)
(B)

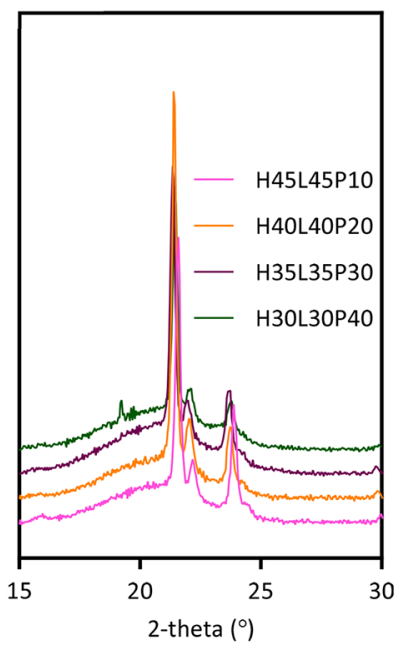

(C)

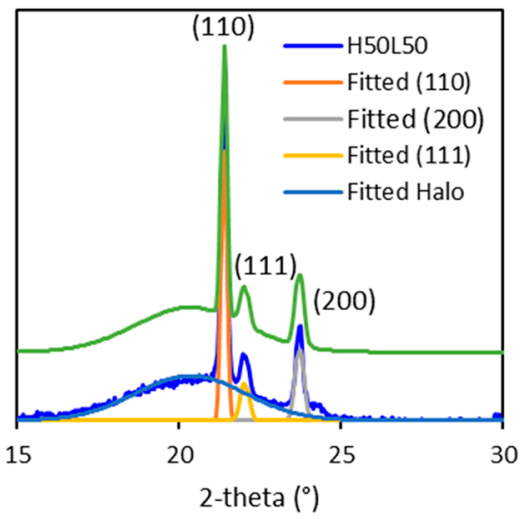

(E)
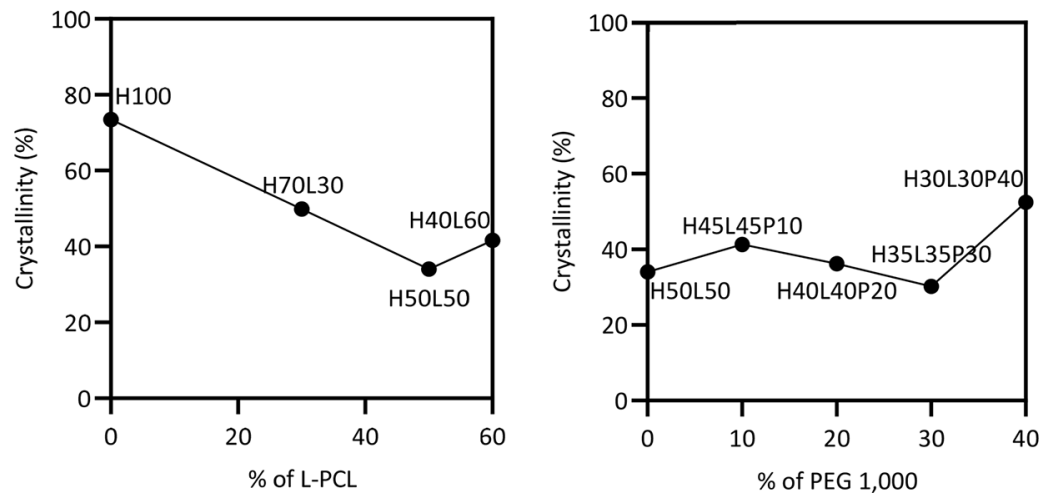

Figure 4. (A, B) XRD of each film formulation. (C) Deconvoluted XRD pattern of H50L50 showing Gaussian fittings of (110), (111), (200), and the amorphous halo. The influence of (D) L-PCL and (E) PEG 1000 on the crystallinity of polymeric films.

(A)

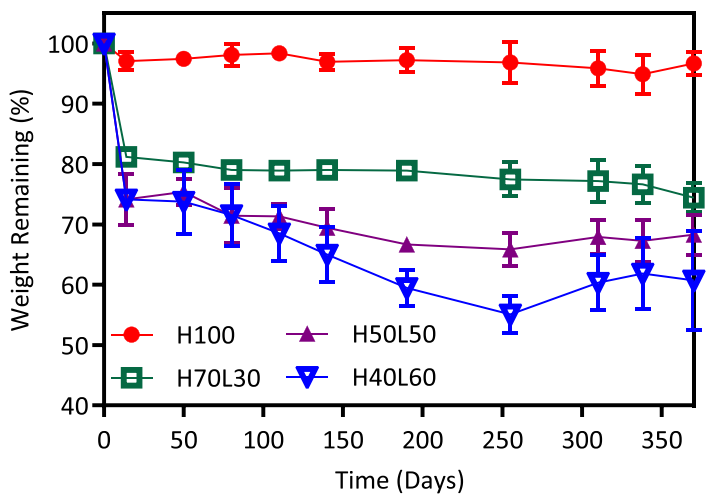

(B)

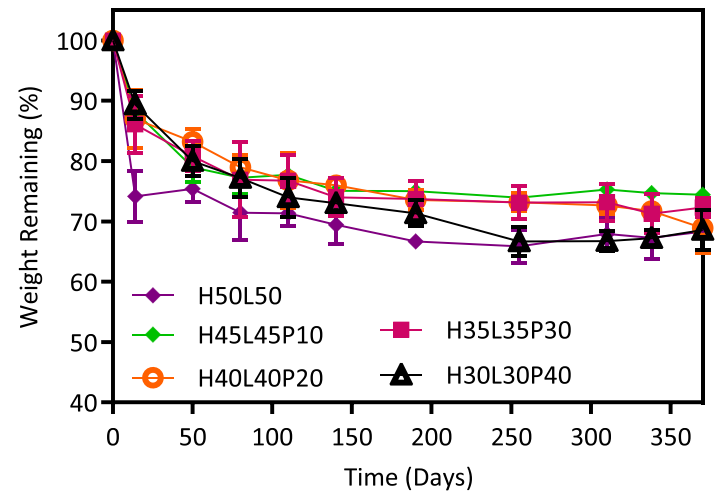

Figure 5. Influence of (A) L-PCL and (B) PEG 1000 content on the degradation rates of the polymeric films (means $\pm \mathrm{SD}, n=3$ ).

compounds. ${ }^{42}$ Addition of L-PCL to the formulation increased the rate of degradation of the films (Figure 5A). This was expected because the rate of degradation is affected by the molecular weight of the polymer. Reduced molecular weight results in a reduced number of ester bonds that need to be cleaved. $^{50}$ L-PCL within the formulations is degraded more quickly than H-PCL; therefore, as the proportion of L-PCL is increased, the rate of degradation is also increased. In addition, L-PCL causes a reduction in crystallinity of the formulations which will contribute to increased degradation. Addition of PEG 1000 to the formulations (Figure 5B) causes a reduction in the degradation rate of these films. This is most likely due to the increased crystallinity that is observed from the addition of PEG 1000 to the formulation.

Contact angle of water with a material indicates the degree of hydrophilicity $^{51}$ and may help to explain any differences in degradation rate of each of the formulations. A more hydrophilic material may have a higher the rate of degradation 
(A)

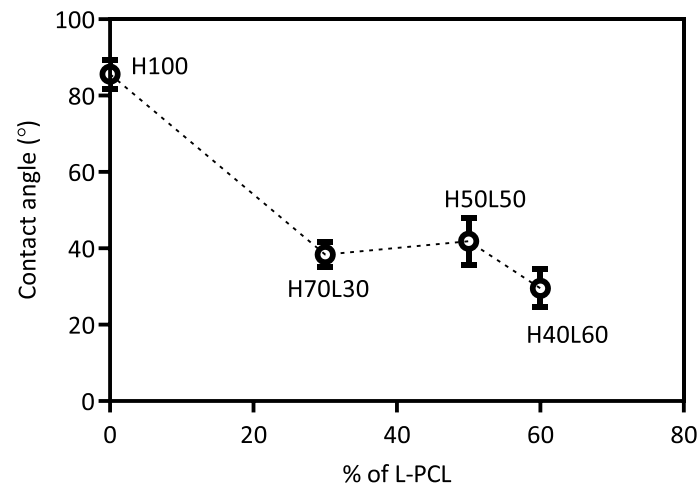

(B)

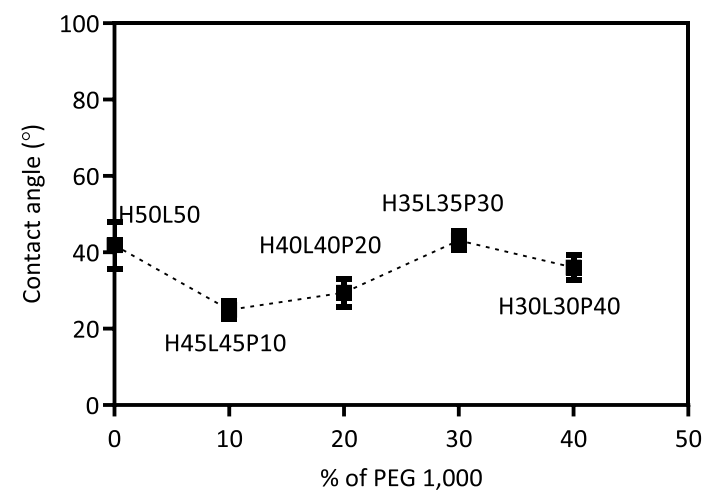

Figure 6. Influence of (A) L-PCL and (B) PEG 1000 content on the contact angle of water with the polymeric films (means \pm SD, $n=3$ ).

as a result of increased water penetration and, therefore, increased rate of hydrolysis of ester bonds. ${ }^{52,53}$ However, this will be dependent on other factors such as crystallinity. The contact angle found for $\mathrm{H} 100$ is lower than results previously reported $\left(123^{\circ 54}\right.$ and $\left.101^{\circ 5}\right)$ for PCL of a similar molecular weight, although contact angle is dependent on factors such as surface properties. For example, a rough surface will result in a higher contact angle for hydrophobic materials but a lower contact angle for hydrophilic materials. ${ }^{51,54,55}$ The addition of L-PCL has a significant $(p<0.05)$ effect in reducing the contact angle of the films (Figure 6A), thereby increasing the hydrophilicity of the films. Increasing the proportion of L-PCL above $30 \%$ did not have a significant $(p>0.05)$ effect on further decreasing the contact angle of the formulations. Jiang et al. ${ }^{55}$ reported that the addition of a hydrophilic compound, hydroxyapatite, resulted in composites with a lower contact angle than those obtained with pure PCL.

The addition of PEG 1000 causes a significant $(p<0.05)$ reduction in contact angle when compared to H50L50 (Figure 6B), but only up to $20 \%$ PEG 1000 content (i.e., formulations H45L45P10 and H40L40P20). For PEG 1000 concentrations above $30 \%$ (i.e., H35L35P30 and H30L30P40), no significant difference $(p>0.05)$ in contact angle was observed. Lin et al. ${ }^{56}$ also reported that increasing the proportion of PEG in amphiphilic co-networks of poly(dimethylsiloxane) resulted in a reduction in their contact angle with deionized water up until a maximum PEG ratio of $6 / 1$. After this point, contact angle remained constant. Wurth et al. ${ }^{57}$ reported that inclusion of oligo-ethylene glycols (OEG) in PCL-OEG-MPO copolymers resulted in a reduction in contact angle of the resulting copolymer, but they only tested this effect up to $8 \%$. This effect could be explained by an interaction between L-PCL and PEG 1000. It is possible that L-PCL and PEG 1000 are interacting to form hydrophilic domains in which L-PCL is surrounding PEG 1000. However, as the concentration of PEG 1000 increases above the concentration of L-PCL, there is insufficient L-PCL to combine with all the PEG 1000, resulting in the slight increase in contact angle observed. Additionally, this theory could explain why the expected increase in degradation rate was not observed with the addition of PEG 1000 and the presence of an additional crystalline peak at $18^{\circ}$ in the XRD studies for formulations containing higher amounts of PEG 1000.

Characterization results from FTIR, DSC, XRD, degradation, and contact angle informed which formulations were investigated further. Four formulations were chosen to be included in further testing: H50L50, H40L60, and H35L35P30 were included to assess the effect of increasing L-PCL concentration and addition of PEG 1000, and H100 was included as a control formulation. The formulations show a range of degradation times and are, therefore, likely to show a range of different release profiles in in vitro release models.

Porosity is an important parameter and will have a significant effect on drug permeation through a polymeric film (Figure 7). ${ }^{58,59}$ Before immersion in PBS ( $\mathrm{pH} 7.4$ ), all membrane formulations showed similar values for porosity. After immersion in PBS (pH 7.4) for 60 days, all films showed an increase in porosity (Figure $7 \mathrm{~A}$ ). This increase was particularly marked for H40L60 and H35L35P30, where the porosity increased by more than $200 \%$ and $300 \%$, respectively, after immersion in PBS ( $\mathrm{pH}$ 7.4) for 60 days (Figure 7B).

Figure $7 \mathrm{C}, \mathrm{D}$ illustrates the log differential intrusion volume analysis of the selected films before and after immersion in PBS ( $\mathrm{pH}$ 7.4). Both $\mathrm{H} 100$ and H40L60 profiles (0 days in PBS (pH 7.4)) were homogeneous, and no significant voids were observed on their surfaces, whereas H50L50 and H35L35P30 exhibited very slight pore size distributions (inset of Figure 7C), below $0.2 \mathrm{~mL} / \mathrm{g}$, which can be attributed to the formation of small surface pits with irregular shapes during the preparation procedure. After immersion in PBS $(\mathrm{pH} 7.4)$ for 60 days, H100, H50L50, and H40L60 showed a monomodal pore size distribution with a peak value centered around 2-3 $\mu \mathrm{m}$. However, the addition of PEG 1000 to the polymer blends in H35L35P30 produced a bimodal shape with an important increase of the pore size distribution intensity, which indicates a larger number of pores with smaller pore sizes of $1-2 \mu \mathrm{m}$.

After immersion in PBS ( $\mathrm{pH}$ 7.4), pores are formed in the polymeric film, as seen in Figure 7E. The addition of PEG in H35L35P30 allows increased water penetration and formation of hydrophilic pores. ${ }^{7}$ Figure $7 \mathrm{~F}$ shows how the hydrophilic compound, fluorescein, congregates to form hydrophilic pores within H35L35P30 and the hydrophobic compound, Nile red, can be seen throughout the rest of the film. These areas of PEG 1000 can dissolve more easily to form pores and facilitate release from these films. It is likely that PEG 1000 domains in these films dissolve and result in the formation of pores.

3.3. Coated Implant Characterization. Images of coated implants (H50P50) filled with MB and IBU sodium are shown in Figure 8A,B. Figure 8C,D shows OCT images of implants filled with MB and IBU sodium and coated with H35L35P3. 
(A)

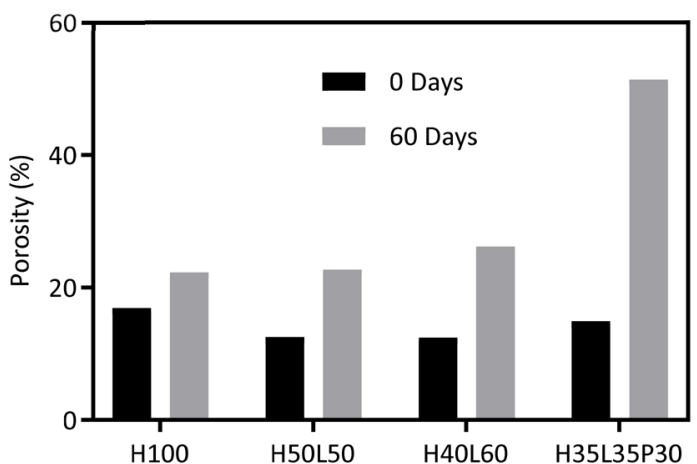

(C)

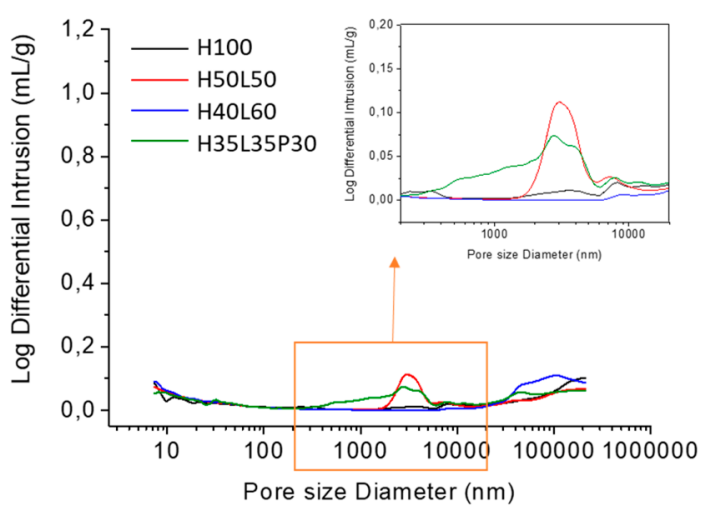

(E)

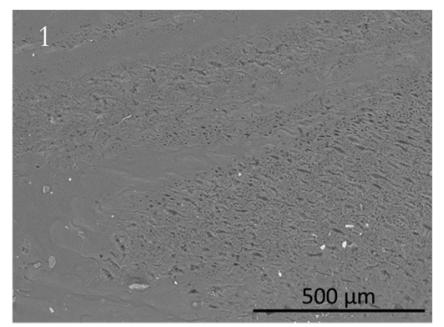

(B)

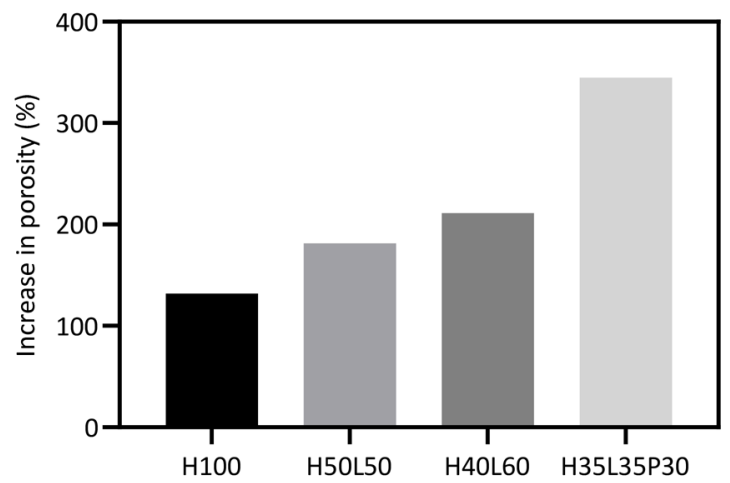

(D)

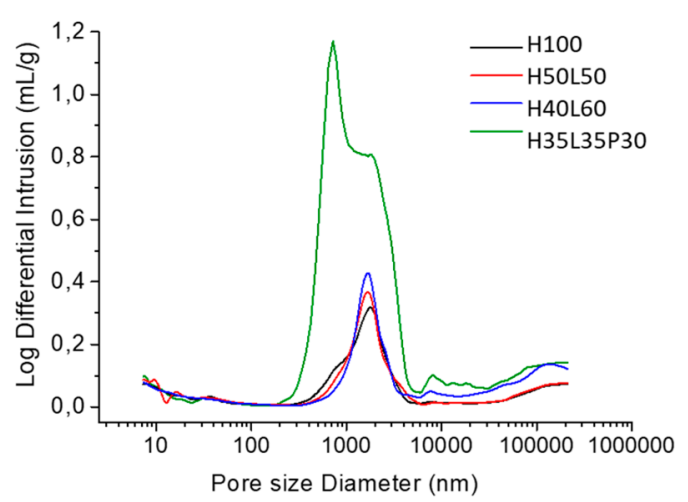

(F)

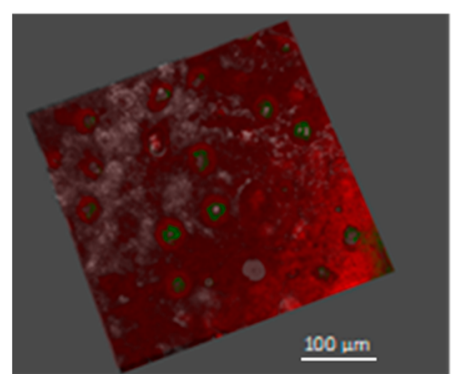

Figure 7. Porosity of films made by solution casting of organic solutions of PCL and PEG 1000. (A) Percentage porosity of each of the films before and after immersion in PBS ( $\mathrm{pH}$ 7.4) for 60 days. (B) Percentage change in porosity of each of the films after immersion in PBS (pH 7.4) for 60 days. Pore size distribution curves of films measured at (C) 0 days and (D) 60 days in PBS (pH 7.4). (E) SEM images of an H35L35P30-coated implant (1) before release and (2) after release. (F) Confocal microscope image of H35L35P30 film (before release) containing Nile red (shown in red) and fluorescein (shown in green).

The materials (PLA, PVA, PCL, and PEG) used were chosen because they are approved by the FDA and are biodegradable (or soluble in the case of PVA). ${ }^{60}$ PLA is broken down by hydrolysis of its ester backbone to form lactic acid, which can be excreted. ${ }^{61}$ PVA is a water-soluble polymer which is biocompatible and has excellent physical properties. ${ }^{62} \mathrm{PCL}$ is degraded to form products which are metabolized by the tricarboxylic acid cycle or renally excreted. ${ }^{63}$ PCL has a relatively long degradation time ranging from months to years, although this is dependent on factors including molecular weight and environmental conditions, such as temperature or pH. ${ }^{50}$ PCL can easily form copolymers with other compounds, for example PEG, to give it more favorable properties, such as increased degradation rate. ${ }^{40,60}$
The architecture and topology of the implants and the coatings were analyzed using a Bruker Skyscan 1172 system $\mu \mathrm{CT}$ (Figure $8 \mathrm{E}-\mathrm{G}$ ). Cross section reconstructions in the $y-z$ plane of coated implants containing MB or IBU sodium were performed, and representative $x-y$ cross sections of implants were used for quantitative analysis. These images provide an appreciation of the drug distribution within the cavity of the implant and the coating surrounding the implant. The dimensional measurements calculated and different points on the implant and implant coating are reported in Figure $8 \mathrm{H}$ and show that there is no significant difference $(p>0.5)$ in the size of the drug core for either model compound. These implants were produced using an FFF printer. However, this type of implant can be produced using alternative AM techniques. 
(A)

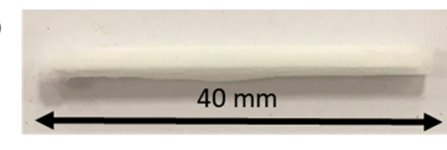

(B)

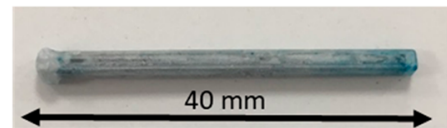

(C)

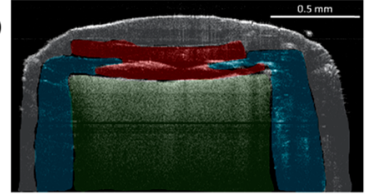

(D)
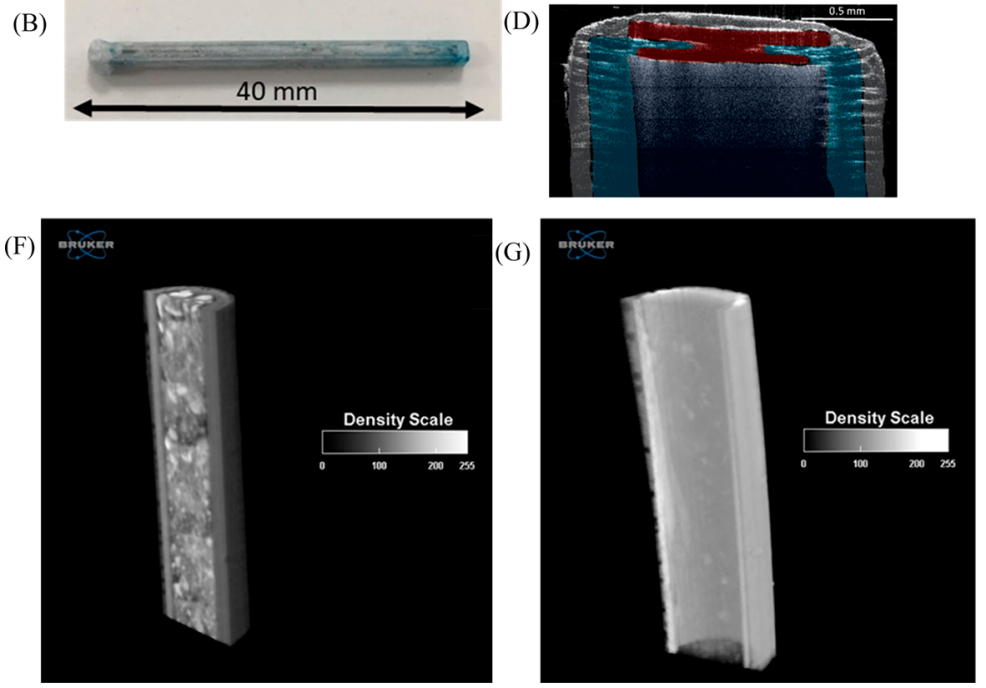

(E)

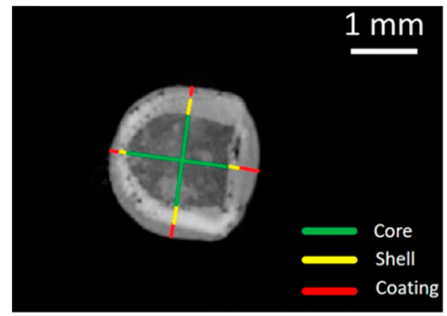

(H)

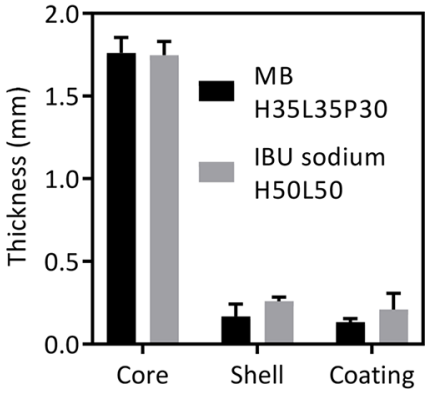

Figure 8. Images of (A) an implant filled with $\mathrm{MB}$ and (B) an implant filled with IBU sodium. OCT images of (C) an implant filled with MB and (D) an implant filled with IBU sodium. MicroCT images of (E) a representative $x-y$ cross section of an implant used for quantitative analysis and cross section reconstructions in the $y-z$ plane of implants containing (F) MB and (G) IBU sodium. (H) Dimensional measurements calculated at different locations over the implant $3 \mathrm{D}$ volume for the core, shell, and coating of the samples reported in $(\mathrm{F})$ and $\mathrm{G})$.

(A)

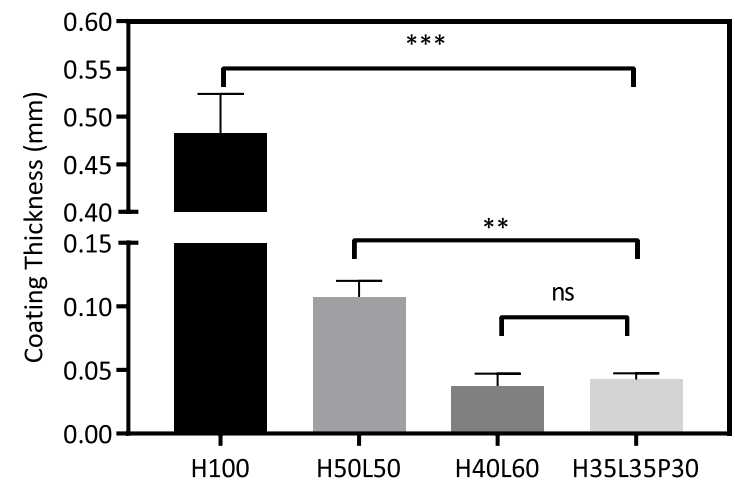

(B)

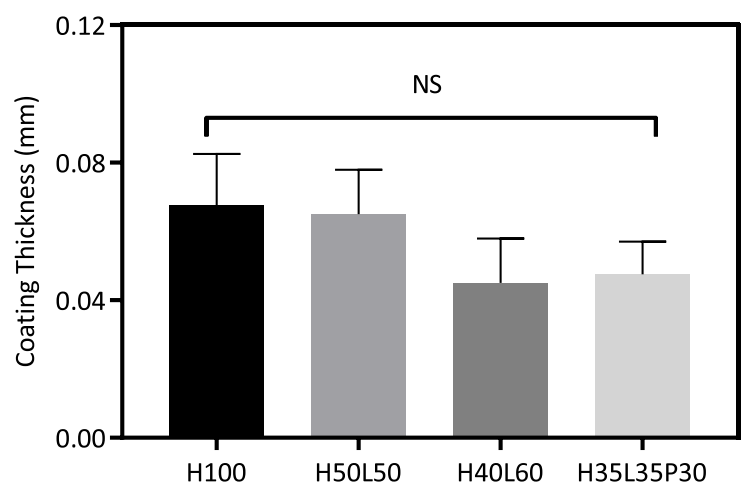

Figure 9. Thicknesses of each of the implant coatings (A) before correction and (B) after thickness correction (means $\pm \mathrm{SD}, n=4) * * * P<0.0001$, $* * P<0.01$, and $\mathrm{ns}=$ no significant difference.

Figure S2 (see Supporting Information) shows an example of this type of implant prepared using a piston-based $3 \mathrm{D}$ printer. This shows the versatility of the proposed design.

The thickness of the coating that was formed by each of the films on the implants was measured (Figure 9A). Due to the increased viscosity of the H100 and H50L50 solutions, they formed significantly thicker $(p<0.01)$ coatings when compared to the other formulations tested. A thicker coating would have an effect on drug release from implants coated with these formulations, as reported by Schlesinger et al. ${ }^{13}$ In that study, the authors produced thin-film PCL devices containing tenofovir alafenamide fumarate (TAF) with film thicknesses of $0.009,0.015$, and $0.026 \mathrm{~mm}$. The devices demonstrated TAF release rates of $4.4,2.2$, and $1.6 \mathrm{mg} /$ day, respectively. ${ }^{13}$ Therefore, the concentration of the coating solution was altered to give coatings with no significant differences in thickness (Figure 9B). The concentrations used were 200, 400, 500 , and $500 \mathrm{mg} / \mathrm{mL}$ for H100, H50L50, H40L60, and H35L35P30, respectively.

3.4. In Vitro Release. Release of both $\mathrm{MB}$ and IBU sodium from uncoated implants was rapid, and $100 \%$ drug release was achieved in 7 days and $80 \mathrm{~min}$ for $\mathrm{MB}$ and IBU sodium, respectively. ${ }^{23}$ The differences in release rate are most likely due to differences in the solubilities and rates of solubilization of the two compounds. MB and IBU sodium have solubilities of 40 and $100 \mathrm{mg} / \mathrm{mL}$, respectively. ${ }^{64,65}$

In order for the drug release to occur from the coated implants, water must first permeate through the film coating to dissolve the PVA "window" and solubilize the drug core. Subsequently, dissolved drug can permeate through the film 
(A)

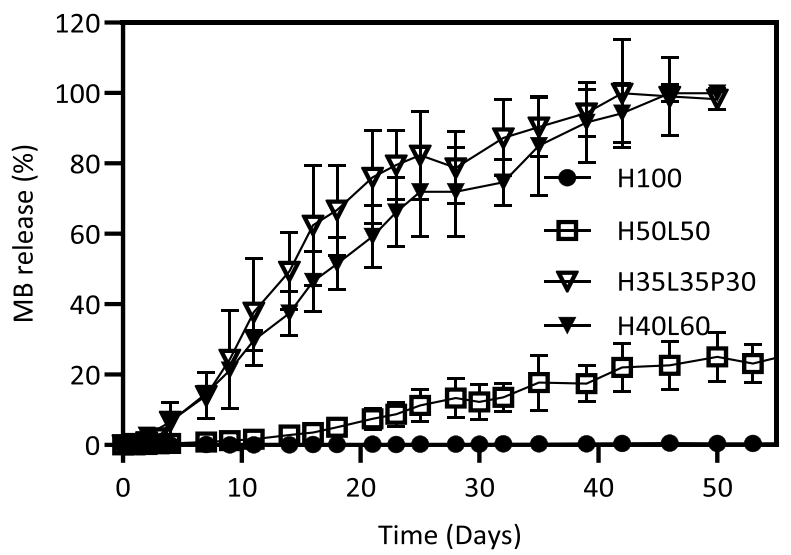

(B)

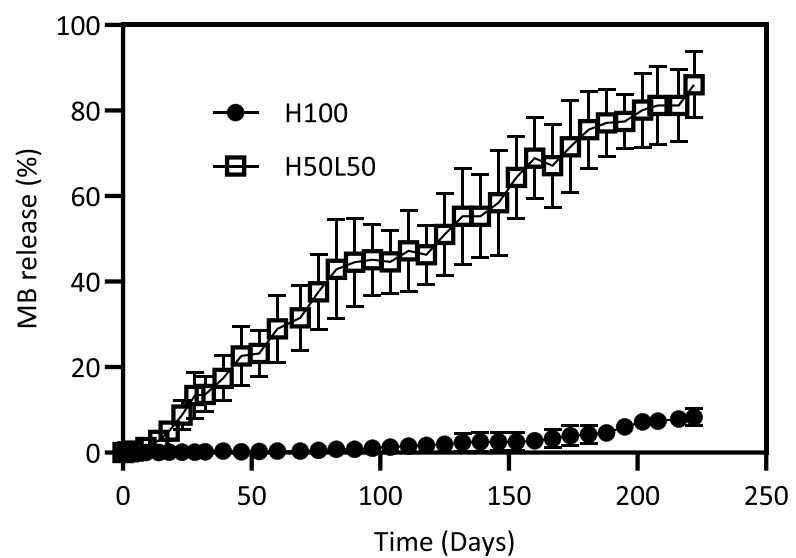

Figure 10. In vitro release profiles of MB-coated implants: (A) release from 0-50 days and (B) release from H100 and H50L50 continued to 160 days (means $\pm \mathrm{SD}, n=3$ ).

and be released into the surrounding media. As expected, the release profiles from the coated implants (Figure 10A,B) are substantially extended when compared to those of the uncoated equivalents. $^{23}$ As expected, H40L60 and H35L35P30 showed the most rapid release profiles, likely because these formulations contained the lowest proportion of H-PCL and H35L35P30 also contained PEG 1000, which can form hydrophilic pores, as seen in Figure 7F. As a result, these films have an increased hydrophilicity, which will increase water penetration, ${ }^{53}$ resulting in an increase in the rate of degradation of these membranes and, therefore, an increased rate of drug release. ${ }^{63,66}$ As expected, the release profile from the implant coated in $\mathrm{H} 100$ was the slowest. This was expected due to the slow degradation of this formulation and reduced pore formation described in previous sections. Implants coated in H50L50 showed a promising release profile for a prolonged drug delivery system.

Similarity and difference factor are statistical tools normally used to compare the dissolution profiles of oral solid dosage forms. ${ }^{67}$ However, they have been successfully used before to compare drug release from different types of formulations such as transdermal patches, ${ }^{68-71}$ implants, $^{72}$ and long-acting injections. ${ }^{73}$ All release profiles were found to be different from each other, as the calculated $F_{1}$ was more than 15 and $F_{2}$ was less than 50 for each case (Table 2). This emphasizes the

Table 2. Difference $\left(F_{1}\right)$ and Similarity $\left(F_{2}\right)$ Factors of Each Release Profile for MB Release from the Coated Implant Design

\begin{tabular}{llcc} 
curve 1 & curve 2 & $F_{1}$ & $F_{2}$ \\
H100 & H50L50 & 97.60 & 33.24 \\
H50L50 & H40L60 & 84.09 & 18.60 \\
H50L50 & H35L30P30 & 89.46 & 16.20 \\
H40L60 & H35L35P30 & 16.82 & 49.29 \\
\hline
\end{tabular}

effect that changing the formulation has on the release profile from the implant. Release rates of each of the release profiles during their linear phases were calculated (Table 3). Subsequently, these release rates were compared. Significant differences $(p<0.05)$ were observed between all formulations except between H40L60 and H35L35P30 ( $p>0.05)$. These results suggest that the release rates of the linear parts of these
Table 3. Release Rate of MB from Each of the Implant Designs (Means $\pm \mathrm{SD}, n=3$ )

implant coating
H100
H50L50
H40L60
H35L35P30

release rate $(\mathrm{mg} /$ day $)$
$0.01 \pm 0.01$
$0.27 \pm 0.02$
$1.52 \pm 0.10$
$1.60 \pm 0.12$

two curves are equivalent. However, $F_{1}$ and $F_{2}$ are used to compare the entire release profile. In this way it can be concluded that H40L60 and H35L35P30 showed equivalent release rates during the linear sections of the curves, but the overall release curves are different whenever they deviate from linearity.

Release experiments were conducted with IBU sodium to allow the effect of drug properties on the release from these coated implants to be investigated (Figure 11). Similar trends

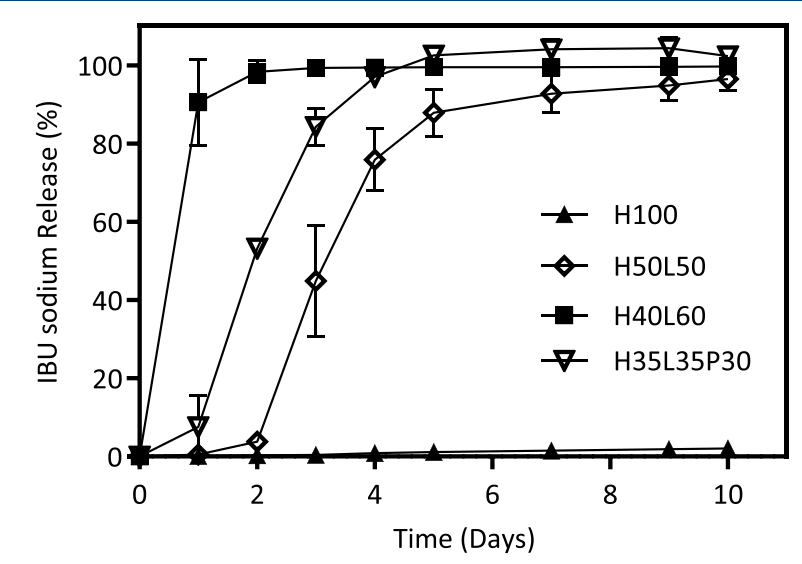

Figure 11. In vitro release profile of IBU sodium from coated implants (means $\pm \mathrm{SD}, n=3$ ).

were observed for $\mathrm{MB}$ and IBU sodium. All coated IBU sodium implants showed more extended release when compared to the uncoated implant. ${ }^{23}$ H40L60 showed the most rapid release rate, followed by H35L35P30 and H50L50, and H100 showed the slowest release rate. Although similar trends are observed for the release rates for all formulations, it is important to note that IBU sodium release was considerably 
faster than MB release from the same coated implant. This increase in release rate for IBU sodium may be attributable to both the solubility of the drug and the dissolution rate of the drug. Therefore, drug properties will have a significant effect on the release profile from these implants, and this highlights the difficulties in prolonging the drug release of highly hydrophilic compounds. Interestingly, when IBU is loaded, the implants coated with H40L60 showed faster drug release than implants coated with H35L35P30. This behavior was not observed in the release of MB. This fact reinforces the conclusion that the permeation of drugs through these PCLbased membranes relies heavily on the nature of the drug.

The release profiles of the coated implants were compared using $F_{1}$ and $F_{2}$, and all release profiles were found to be different (Table 4). These results suggest that all release

Table 4. Difference $\left(F_{1}\right)$ and Similarity $\left(F_{2}\right)$ Factors of Each Release Profile for IBU Sodium Release from the Coated Implant Design

\begin{tabular}{llcc}
\multicolumn{1}{c}{ curve 1 } & \multicolumn{1}{c}{ curve 2 } & $F_{1}$ & $F_{2}$ \\
H100 & H50L50 & 98.66 & 14.95 \\
H50L50 & H35L35P30 & 48.34 & 26.16 \\
H50L50 & H40L60 & 96.65 & 22.44 \\
H35L35P30 & H40L60 & 65.57 & 15.71 \\
\hline
\end{tabular}

profiles were different from each other, as in all cases the calculated $F_{1}$ was more than 15 and $F_{2}$ was less than 50 . Release rates of each of the release profiles (Table 5) were

Table 5. Release Rate of Each of the Implant Designs $($ Means $\pm \mathrm{SD}, n=3$ )

$\begin{array}{lc}\text { implant coating } & \text { release rate }(\mathrm{mg} / \text { day }) \\ \text { H100 } & 0.15 \pm 0.10 \\ \text { H50L50 } & 19.73 \pm 1.28 \\ \text { H40L60 } & 34.09 \pm 1.04 \\ \text { H35L35P30 } & 20.96 \pm 2.15\end{array}$

compared, and significant differences $(p<0.05)$ were observed between all formulations except H50L50 and H35L35P30 ( $p>$ 0.05 ). As explained before, this takes into account only the release rates of the linear regions and not the release plot. It can be clearly seen in Figure 11 that the release profiles of these two types of implants are different. Moreover, this was confirmed after calculating the similarity and difference factors $\left(F_{1}\right.$ and $\left.F_{2}\right)$.

This work demonstrates the impact that both implant design and drug properties have on the release profile from an implantable drug delivery device. Table 4 summarizes the release rate from each of the implants investigated in this work. Release rates ranging from 0.01 to $34.09 \mathrm{mg} /$ day were achieved as a result of changing the coating formulation and the differing properties of the drug within the implant. No significant difference $(p>0.05)$ between the release rates of $\mathrm{MB}$ and IBU sodium from H100 implants were observed; however, significant differences $(p<0.05)$ for all other formulations were observed. These results emphasize the difficulties in sustaining the release of hydrophilic drugs. IBU sodium is more hydrophilic than $\mathrm{MB}$ and, as such, has additional challenges to extending its release profile. The work in this paper is a proof of concept using model drugs; however, the implant coating could be modified for specific drugs, or additionally extra excipients could be added to the powder drug core to influence the rate of release.

There are many conditions that this type of implant may be suitable for. For example, an implant coated with H35L35P30 could be suitable for pre-exposure prophylaxis (PrEP) of HIV using TAF, as it is estimated that a dose of less than $2.8 \mathrm{mg} /$ day could be effective for this purpose, if delivered subcutaneously. ${ }^{13}$ This work focuses on prolonging the delivery of hydrophilic molecules, such as ropinirole (maximum daily dose of $4 \mathrm{mg}$ for restless leg syndrome ${ }^{74}$ ) or local delivery of gentamicin after surgery. However, similar implants could be designed for potent hydrophobic drugs and conditions including risperidone for chronic psychosis (daily dose $4 \mathrm{mg}^{75}$ ) or levothyroxine for hypothyroidism (daily dose $\left.100-200 \mu \mathrm{g}^{76}\right)$. However, further work needs to be conducted to specifically design an implant for each release rate required. The flexibility of the manufacturing techniques used in this work may also allow for the design of complex implantable devices which could deliver multiple drugs at differing rates, as is the case for combinations of hormonal contraceptives: ${ }^{77}$ ethinylestradiol (20-35 $\mu \mathrm{g} /$ day), levonorgestrel (150 $\mu \mathrm{g} /$ day $)$, and gestodene $(75 \mu \mathrm{g} /$ day $)$, among others.

\section{CONCLUSION}

In this work, hollow implants with dimensions similar to those already available on the market were successfully produced using AM. Subsequently, the implants were coated with a degradable polymeric film coating to control drug release. Eight film formulations were made from H-PCL, L-PCL, and PEG 1000 and characterized using a variety of techniques including DSC, porosity, $\mu$-CT, and OCT, among others. The most promising formulations underwent in vitro release testing using two model compounds. Release rates ranging from 0.01 to $34.09 \mathrm{mg} /$ day were obtained and could be easily modified by changing the formulation of the polymeric coating. The results presented in this work demonstrate the flexibility of the implants produced and highlight their potential for sustaining the release of hydrophilic compounds. However, the manufacturing methods do not limit the applications to hydrophilic drugs, and the implant could be tailored to the properties of any drug compound. The present work was a proof-of-concept study, and future work will aim to develop an implant with a specific release rate for a drug and condition. Additionally, as AM is still a relatively new technique in the pharmaceutical industry, approaches to scale up this method of manufacture need to be investigated.

\section{ASSOCIATED CONTENT}

\section{SI Supporting Information}

The Supporting Information is available free of charge at https://pubs.acs.org/doi/10.1021/acs.molpharmaceut.0c00515.

Figure S1, Representative DSC thermograms of PCLPEG mixtures to demonstrate the effect of molecular weight on the presence of two meting points; Figure S2, Images of implants made using a piston-based 3D printer (PDF) 


\section{AUTHOR INFORMATION}

\section{Corresponding Author}

Eneko Larrañeta - School of Pharmacy, Queen's University Belfast, Belfast BT9 7BL, U.K.; ๑ orcid.org/0000-00033710-0438; Email: e.larraneta@qub.ac.uk

\section{Authors}

Sarah A. Stewart - School of Pharmacy, Queen's University Belfast, Belfast BT9 7BL, U.K.; $\odot$ orcid.org/0000-00030230-4625

Juan Domínguez-Robles - School of Pharmacy, Queen's University Belfast, Belfast BT9 7BL, U.K.

Victoria J. McIlorum - School of Pharmacy, Queen's University Belfast, Belfast BT9 7BL, U.K.

Zoilo Gonzalez - Instituto De Cerámica y Vidrio, CSIC, 28049 Madrid, Spain

Emilia Utomo - School of Pharmacy, Queen's University Belfast, Belfast BT9 7BL, U.K.

Elena Mancuso - Nanotechnology and Integrated BioEngineering Centre (NIBEC), Ulster University, Jordanstown BT37 OQB, U.K.; ๑ orcid.org/0000-0003-1742-1656

Dimitrios A. Lamprou - School of Pharmacy, Queen's University Belfast, Belfast BT9 7BL, U.K.; $\odot$ orcid.org/00000002-8740-1661

Ryan F. Donnelly - School of Pharmacy, Queen's University Belfast, Belfast BT9 7BL, U.K.; ๑ orcid.org/0000-00020766-4147

Complete contact information is available at:

https://pubs.acs.org/10.1021/acs.molpharmaceut.0c00515

\section{Notes}

The authors declare no competing financial interest.

\section{ACKNOWLEDGMENTS}

This work was financially supported by the Wellcome Trust (UNS40040 and WT094085MA). S.A.S. is a Ph.D. candidate funded by a Department for the Economy (Northern Ireland) studentship.

\section{REFERENCES}

(1) Rajgor, N.; Bhaskar, V.; Patel, M. Implantable drug delivery systems: An overview. Syst. Rev. Pharm. 2011, 2, 91.

(2) Langer, R. New methods of drug delivery. Science (Washington, DC, U. S.) 1990, 249, 1527-1533.

(3) Dash, A. K.; Cudworth, G. C. Therapeutic applications of implantable drug delivery systems. J. Pharmacol. Toxicol. Methods 1998, 40, 1-12.

(4) Fialho, S. L.; da Silva Cunha, A. Manufacturing techniques of biodegradable implants intended for intraocular application. Drug Delivery 2005, 12, 109-116.

(5) Boia, R.; Dias, P. A. N.; Martins, J. M.; Galindo-Romero, C.; Aires, I. D.; Vidal-Sanz, M.; Agudo-Barriuso, M.; de Sousa, H. C.; Ambrósio, A. F.; Braga, M. E. M.; et al. Porous poly( $\varepsilon$-caprolactone) implants: A novel strategy for efficient intraocular drug delivery. $J$. Controlled Release 2019, 316, 331-348.

(6) Kumar, A.; Pillai, J. Implantable drug delivery systems. In Nanostructures for the engineering of cells, tissues and organs; Elsevier, 2018; pp 473-511.

(7) Stewart, S. A.; Domínguez-Robles, J.; Donnelly, R. F.; Larrañeta, E. Implantable polymeric drug delivery devices: Classification, manufacture, materials, and clinical Applications. Polymers (Basel, Switz.) 2018, 10, 1379.

(8) Chertok, B.; Webber, M. J.; Succi, M. D.; Langer, R. Drug delivery interfaces in the 21 st century: From science fiction ideas to viable technologies. Mol. Pharmaceutics 2013, 10, 3531-3543.
(9) Affandi, B.; Santoso, S. S. I.; Djajadilaga; Hadisaputra, W.; Moeloek, F. A.; Prihartono, J.; Lubis, F.; Samil, R. S. Five-year experience with norplant ${ }^{\circledR}$. Contraception 1987, 36, 417-428.

(10) Mansour, D. Nexplanon ${ }^{\circledR}$ : What Implanon ${ }^{\circledR}$ did next. J. Fam. Plan. Reprod. Health Care 2010, 36, 187-189.

(11) Macoul, K. L.; Pavan-Langston, D. Pilocarpine ocusert system for sustained control of ocular hypertension. Arch. Ophthalmol. 1975, 93, 587-590.

(12) Sun, H.; Mei, L.; Song, C.; Cui, X.; Wang, P. The in vivo degradation, absorption and excretion of PCL-based implant. Biomaterials 2006, 27, 1735-1740.

(13) Schlesinger, E.; Johengen, D.; Luecke, E.; Rothrock, G.; McGowan, I.; van der Straten, A.; Desai, T. A tunable, biodegradable, thin-film polymer device as a long-acting implant delivering tenofovir alafenamide fumarate for HIV pre-exposure prophylaxis. Pharm. Res. 2016, 33, 1649-1656.

(14) Hsu, W. H.; Chang, H. M.; Lee, Y. L.; Prasannan, A.; Hu, C. C.; Wang, J. S.; Lai, J. Y.; Yang, J. M.; Jebaranjitham, N.; Tsai, H. C. Biodegradable polymer-nanoclay composites as intestinal sleeve implants installed in digestive tract for obesity and type 2 diabetes treatment. Mater. Sci. Eng., C 2020, 110, 110676.

(15) Lee, S. J.; Jo, H. H.; Lim, K. S.; Lim, D.; Lee, S.; Lee, J. H.; Kim, W. D.; Jeong, M. H.; Lim, J. Y.; Kwon, I. K. Heparin coating on 3D printed poly (1-lactic acid) biodegradable cardiovascular stent via mild surface modification approach for coronary artery implantation. Chem. Eng. J. 2019, 378, 122116

(16) Steffens, L.; Morás, A. M.; Arantes, P. R.; Masterson, K.; Cao, Z.; Nugent, M.; Moura, D. J. Electrospun PVA-Dacarbazine nanofibers as a novel nano brain-implant for treatment of glioblastoma: in silico and in vitro characterization. Eur. J. Pharm. Sci. 2020, 143, 105183.

(17) Lee, P. J.; Ho, C. C.; Hwang, C. S.; Ding, S. J. Improved physicochemical properties and biocompatibility of stainless steel implants by PVA/ZrO2-based composite coatings. Surf. Coat. Technol. 2014, 258, 374-380.

(18) Goyanes, A.; Wang, J.; Buanz, A.; Martínez-Pacheco, R.; Telford, R.; Gaisford, S.; Basit, A. W. 3D Printing of Medicines: Engineering Novel Oral Devices with Unique Design and Drug Release Characteristics. Mol. Pharmaceutics 2015, 12, 4077-4084.

(19) Cho, H.; Jammalamadaka, U.; Tappa, K.; Egbulefu, C.; Prior, J.; Tang, R.; Achilefu, S. 3D printing of poloxamer 407 nanogel discs and their applications in adjuvant ovarian cancer therapy. Mol. Pharmaceutics 2019, 16, 552-560.

(20) Arpicco, S.; Battaglia, L.; Brusa, P.; Cavalli, R.; Chirio, D.; Dosio, F.; Gallarate, M.; Milla, P.; Peira, E.; Rocco, F.; et al. Recent studies on the delivery of hydrophilic drugs in nanoparticulate systems. J. Drug Delivery Sci. Technol. 2016, 32, 298-312.

(21) Park, K. Drug delivery research: The invention cycle. Mol. Pharmaceutics 2016, 13, 2143-2147.

(22) Yang, J.; Wang, F.; Yuan, H.; Zhang, L.; Jiang, Y.; Zhang, X.; Liu, C.; Chai, L.; Li, H.; Stenzel, M. Recent advances in ultra-small fluorescent $\mathrm{Au}$ nanoclusters toward oncological research. Nanoscale 2019, 11, 17967-17980.

(23) Stewart, S. A.; Domínguez-Robles, J.; Mcllorum, V. J.; Mancuso, E.; Lamprou, D. A.; Donnelly, R. F.; Larrañeta, E. Development of a Biodegradable Subcutaneous Implant for Prolonged Drug Delivery Using 3D Printing. Pharmaceutics 2020, 12, 105 .

(24) Sownthari, K.; Suthanthiraraj, S. A. Synthesis and characterization of an electrolyte system based on a biodegradable polymer. eXPRESS Polym. Lett. 2013, 7, 495-504.

(25) Faibish, R. S.; Yoshida, W.; Cohen, Y. Contact angle study on polymer-grafted silicon wafers. J. Colloid Interface Sci. 2002, 256, 341350.

(26) Mathew, E.; Domínguez-Robles, J.; Stewart, S. A.; Mancuso, E.; O’Donnell, K.; Larrañeta, E.; Lamprou, D. A. Fused deposition modeling as an effective tool for anti-infective dialysis catheter fabrication. ACS Biomater. Sci. Eng. 2019, 5, 6300-6310. 
(27) Domínguez-Robles, J.; Mancinelli, C.; Mancuso, E.; GarcíaRomero, I.; Gilmore, B. F.; Casettari, L.; Larrañeta, E.; Lamprou, D. A. 3D printing of drug-loaded thermoplastic polyurethane meshes: A potential material for soft tissue reinforcement in vaginal surgery. Pharmaceutics 2020, 12, 63.

(28) The British Pharmacopeia Commission, British Pharmacopoeia, https://www.pharmacopoeia.com/bp-2020?date $=2020-01-01$ (accessed Aug 30, 2019).

(29) Larrañeta, E.; Martínez-Ohárriz, C.; Vélaz, I.; Zornoza, A.; Machín, R.; Isasi, J. R. In vitro release from reverse poloxamine $/ \alpha$ cyclodextrin matrices: Modelling and comparison of dissolution profiles. J. Pharm. Sci. 2014, 103, 197-206.

(30) Costa, P.; Sousa Lobo, J. M. Modeling and comparison of dissolution profiles. Eur. J. Pharm. Sci. 2001, 13, 123-133.

(31) O'Hara, T.; Dunne, A.; Kinahan, A.; Cunningham, S.; Stark, P.; Devane, J.Review of methodologies for the comparison of dissolution profile data. In In Vitro-in Vivo Correlations; Young, D., Devane, J. G., Butler, J., Eds.; Advances in Experimental Medicine and Biology 423; Springer: Boston, MA, 1997; pp 167-171.

(32) Domínguez-Robles, J.; Martin, N.; Fong, M.; Stewart, S. A.; Irwin, N.; Rial-Hermida, M.; Donnelly, R.; Larrañeta, E. Antioxidant PLA composites containing lignin for 3D printing applications: A potential material for healthcare applications. Pharmaceutics 2019, 11, 165.

(33) Larrañeta, E.; Stewart, S.; Fallows, S. J.; Birkhäuer, L. L.; McCrudden, M. T. C.; Woolfson, A. D.; Donnelly, R. F. A facile system to evaluate in vitro drug release from dissolving microneedle arrays. Int. J. Pharm. 2016, 497, 62-69.

(34) Saniei, H.; Mousavi, S. Surface modification of PLA 3D-printed implants by electrospinning with enhanced bioactivity and cell affinity. Polymer 2020, 196, 122467.

(35) Bhattarai, R. S.; Das, A.; Alzhrani, R. M.; Kang, D.; Bhaduri, S. B.; Boddu, S. H. S. Comparison of electrospun and solvent cast polylactic acid (PLA)/poly(vinyl alcohol) (PVA) inserts as potential ocular drug delivery vehicles. Mater. Sci. Eng., C 2017, 77, 895-903.

(36) Funk, S.; Miller, M. M.; Mishell, D. R.; Archer, D. F.; Poindexter, A.; Schmidt, J.; Zampaglione, E. Safety and efficacy of Implanon, a single-rod implantable contraceptive containing etonogestrel. Contraception 2005, 71, 319-326.

(37) Zhang, W.; Ullah, I.; Shi, L.; Zhang, Y.; Ou, H.; Zhou, J.; Ullah, M. W.; Zhang, X.; Li, W. Fabrication and characterization of porous polycaprolactone scaffold via extrusion-based cryogenic 3D printing for tissue engineering. Mater. Des. 2019, 180, 107946.

(38) Witt, S.; Scheper, T.; Walter, J. Production of polycaprolactone nanoparticles with hydrodynamic diameters below $100 \mathrm{~nm}$. Eng. Life Sci. 2019, 19, 658-665.

(39) Visan, A. I.; Popescu-Pelin, G.; Gherasim, O.; Mihailescu, A.; Socol, M.; Zgura, I.; Chiritoiu, M.; Elena Sima, L.; Antohe, F.; Ivan, L.; et al. Long-Term Evaluation of Dip-Coated PCL-Blend-PEG Coatings in Simulated Conditions. Polymers (Basel, Switz.) 2020, 12, 717.

(40) Nair, L. S.; Laurencin, C. T. Biodegradable polymers as biomaterials. Prog. Polym. Sci. 2007, 32, 762-798.

(41) Kmiec, E.; Borjigin; Eskridge; Niamat; Strouse, B.; Bialk. Electrospun fiber membranes enable proliferation of genetically modified cells. Int. J. Nanomed. 2013, 855.

(42) Zehnder, T.; Freund, T.; Demir, M.; Detsch, R.; Boccaccini, A. Fabrication of Cell-Loaded Two-Phase 3D Constructs for Tissue Engineering. Materials 2016, 9, 887.

(43) Perstorp, Perstorp CAPA 2054, https://www.tri-iso.com/ perstorp-capa-2054.html (accessed Apr 29, 2020).

(44) Sigma-Aldrich, Poly(ethylene glycol), https://www. sigmaaldrich.com/catalog/product/sial/81190?lang=en\&region=GB (accessed Apr 29, 2020).

(45) Mirahamad, A.; Sadrameli, S. M.; Seifi, H. Theoretical and experimental studies on a latent heat thermal energy storage system (LHTES) containing flat slabs of phase change materials. Int. J. Smart Grid Clean Energy 2014, 3, 234-240.
(46) Luo, C.; Chen, W.; Gao, Y. Fractional crystallization behavior of PCL and PEG in blends. Polym. Sci., Ser. A 2016, 58, 196-205.

(47) Douglas, P.; Albadarin, A. B.; Sajjia, M.; Mangwandi, C.; Kuhs, M.; Collins, M. N.; Walker, G. M. Effect of poly(ethylene glycol) on the mechanical and thermal properties of bioactive poly $(\varepsilon$ caprolactone) melt extrudates for pharmaceutical applications. Int. J. Pharm. 2016, 500, 179-186.

(48) Li, F.-J.; Zhang, S.-D.; Liang, J.-Z.; Wang, J.-Z. Effect of polyethylene glycol on the crystallization and impact properties of polylactide-based blends. Polym. Adv. Technol. 2015, 26, 465-475.

(49) Dash, T. K.; Konkimalla, V. B. Polymeric dodification and its implication in drug delivery: Poly- $\varepsilon$-caprolactone (PCL) as a model polymer. Mol. Pharmaceutics 2012, 9, 2365-2379.

(50) Woodruff, M. A.; Hutmacher, D. W. The return of a forgotten polymer-Polycaprolactone in the 21st century. Prog. Polym. Sci. 2010, 35, 1217-1256.

(51) Kurusu, R. S.; Demarquette, N. R. Surface modification to control the water wettability of electrospun mats. Int. Mater. Rev. 2019, 64, 249-287.

(52) Jenkins, M. J.; Harrison, K. L. The effect of molecular weight on the crystallization kinetics of polycaprolactone. Polym. Adv. Technol. 2006, 17, 474-478.

(53) Castilla-Cortázar, I.; Más-Estellés, J.; Meseguer-Dueñas, J. M.; Escobar Ivirico, J. L.; Marí, B.; Vidaurre, A. Hydrolytic and enzymatic degradation of a poly( $\varepsilon$-caprolactone) network. Polym. Degrad. Stab. 2012, 97, 1241-1248.

(54) Bolbasov, E.; Goreninskii, S.; Tverdokhlebov, S.; Mishanin, A.; Viknianshchuk, A.; Bezuidenhout, D.; Golovkin, A. Comparative study of the physical, topographical and biological properties of electrospinning PCL, PLLA, their blend and copolymer scaffolds. IOP Conf. Ser. Mater. Sci. Eng. 2018, 350, 012012.

(55) Jiang, W.; Shi, J.; Li, W.; Sun, K. Morphology, wettability, and mechanical properties of polycaprolactone/hydroxyapatite composite scaffolds with interconnected pore structures fabricated by a minideposition system. Polym. Eng. Sci. 2012, 52, 2396-2402.

(56) Lin, G.; Zhang, X.; Kumar, S. R.; Mark, J. E. Improved hydrophilicity from poly(ethylene glycol) in amphiphilic conetworks with poly(dimethylsiloxane). Silicon 2009, 1, 173-181.

(57) Wurth, J. J.; Blumenthal, N. R.; Shastri, V. P. Hydrophilization of poly(caprolactone) copolymers through introduction of oligo(ethylene glycol) moieties. PLoS One 2014, 9, e99157.

(58) Ullah, A.; Kim, C. M.; Kim, G. M. Porous polymer coatings on metal microneedles for enhanced drug delivery. R. Soc. Open Sci. 2018, 5, 171609.

(59) Häbel, H.; Andersson, H.; Olsson, A.; Olsson, E.; Larsson, A.; Särkkä, A. Characterization of pore structure of polymer blended films used for controlled drug release. J. Controlled Release 2016, 222, 151158.

(60) Middleton, J. C.; Tipton, A. J. Synthetic biodegradable polymers as orthopedic devices. Biomaterials 2000, 21, 2335-2346.

(61) Grizzi, I.; Garreau, H.; Li, S.; Vert, M. Hydrolytic degradation of devices based on poly(dl-lactic acid) size-dependence. Biomaterials 1995, 16, 305-311.

(62) Paradossi, G.; Cavalieri, F.; Chiessi, E.; Spagnoli, C.; Cowman, M. Poly(vinyl alcohol) as versatile biomaterial for potential biomedical applications. J. Mater. Sci.: Mater. Med. 2003, 14, 687691.

(63) Escobar Ivirico, J. L.; Salmerón Sánchez, M.; Sabater i Serra, R.; Meseguer Dueñas, J. M.; Gómez Ribelles, J. L.; Monleón Pradas, M. Structure and properties of poly $(\varepsilon$-caprolactone $)$ networks with modulated water uptake. Macromol. Chem. Phys. 2006, 207, 21952205.

(64) Sigma-Aldrich, Ibuprofen sodium salt, https://www. sigmaaldrich.com/catalog/product/sial/i1892?lang=en\&region=GB (accessed Mar 8, 2019).

(65) Pubchem, Methylene Blue, https://pubchem.ncbi.nlm.nih.gov/ compound/6099\#section=Top (accessed Mar 8, 2019).

(66) Sabater i Serra, R.; Escobar Ivirico, J. L.; Meseguer Dueñas, J. M.; Andrio Balado, A.; Gómez Ribelles, J. L.; Salmerón Sánchez, M. 
Dielectric relaxation spectrum of poly ( $\varepsilon$-caprolactone) networks hydrophilized by copolymerization with 2-hydroxyethyl acrylate. Eur. Phys. J. E: Soft Matter Biol. Phys. 2007, 22, 293-302.

(67) U.S. Food and Drug Administration, Dissolution testing of immediate release solid oral dosage forms, August 1997, https:// www.fda.gov/media/70936/download (accessed Jul 9, 2020).

(68) Polli, J. E.; Rekhi, G. S.; Augsburger, L. L.; Shah, V. P. Methods to compare dissolution profiles and a rationale for wide dissolution specifications for metoprolol tartrate tablets. J. Pharm. Sci. 1997, 86, 690-700.

(69) Dua, K.; Ramana, M. V.; Sara, U. V. S.; Agrawal, D. K.; Pabreja, K.; Chakravarthi, S. Preparation and evaluation of transdermal plasters containing norfloxacin: a novel treatment for burn wound healing. Eplasty 2010, 10, e44.

(70) Prajapati, S. T.; Patel, C. G.; Patel, C. N. Formulation and evaluation of transdermal patch of repaglinide. ISRN Pharm. 2011, 2011, 651909.

(71) Larrañeta, E.; Lutton, R. E. M.; Brady, A. J.; Vicente-Pérez, E. M.; Woolfson, A. D.; Thakur, R. R. S.; Donnelly, R. F. Microwaveassisted preparation of hydrogel-forming microneedle arrays for transdermal drug delivery applications. Macromol. Mater. Eng. 2015, $300,586-595$.

(72) Cheng, L.; Lei, L.; Guo, S. In vitro and in vivo evaluation of praziquantel loaded implants based on PEG/PCL blends. Int. J. Pharm. 2010, 387, 129-138.

(73) Wright, J. C. Long acting injections and implants; Wright, J. C., Burgess, D. J., Eds.; Springer US: Boston, MA, 2012.

(74) Joint formulary committee, Ropinirole - BNF monograph, https://bnf.nice.org.uk/drug/ropinirole.html (accessed May 1, 2020).

(75) Joint formulary committee, Risperidone - BNF monograph, https://bnf.nice.org.uk/drug/risperidone.html\#indicationsAndDoses (accessed Apr 17, 2020).

(76) Joint formulary committee, Levothyroxine sodium - BNF monograph, https://bnf.nice.org.uk/drug/levothyroxine-sodium. html\#indicationsAndDoses (accessed Jan 22, 2020).

(77) Joint formulary committee, Contraceptives, hormonal - BNF monograph, https://bnf.nice.org.uk/treatment-summary/ contraceptives-hormonal.html (accessed Apr 17, 2020). 